\title{
Hurricane Sandy: Lessons Learned, Again
}

David M. Abramson, PhD; Irwin Redlener, MD

$\mathrm{H}$

urricane Sandy was a sobering reminder to those of us who call New York home that it is a port city and subject to the whims of wind and water. The storm itself was massive: climatologically, a thousand miles wide at its peak; economically, an estimated excess of $\$ 50$ billion in damages. In the New York metropolitan area, 97 people died in the storm, thousands were displaced from their homes, and 2 major hospitals required perilous evacuations even as the hurricaneforce winds engulfed the metropolitan region.

Vivid scenes of "medical humanitarianism" played out in the days and weeks after Hurricane Sandy devastated neighborhoods in New York and New Jersey. On streets in Rockaway, Queens, doctors in mobile medical units treated exacerbations of asthma among teenagers who were suffering in cold, dank, and powerless apartments without their rescue medications. The doctors occasionally climbed 15 flights of stairs to make house calls. In a Bronx gymnasium, hospital nurses and clinicians who had volunteered to staff a functional needs shelter were confronted with more than a hundred medically fragile patients from adult homes who suddenly appeared at the shelter without medical records or accompanying staff. In Manhattan, on the night the hurricane made landfall, hundreds of medical students, residents, and nurses were pressed into service to carry hospital patients down darkened flights of stairs as generators failed.

Medical heroism? Perhaps. Or a stark illustration of the preparedness gaps that still exist. Each of these scenarios reflect a failure of systems, some more predictable than others. And each of these scenarios represents practices driven as much by goodwill or desperation as by science and evidence. At least in theory, all of these situations could have been prevented with the right planning.

Many of the issues that emerged during and after Hurricane Sandy were not within the power of either medicine or public health to fix. Some of the storm's biggest impacts were a consequence of energy failures at both macro and micro levels. The disruption of the region's fuel distribution network resulted in severe gas shortages, which affected medical and public health workforces, among others, and disrupted the area's supply chain for nearly 2 weeks. Locally, the energy disruptions had direct effects-at least 8 of the deaths attributed to Sandy in the New York area were the result of carbon monoxide poisoning in households using generators or stoves for heat, and the evacuation of 200 patients from New York University Langone Medical Center was the result of a fuel pump failure.

Another critical issue was the public's response to risk communications, particularly the mandatory evacuation orders given for residents along the coast where an extraordinary storm surge was expected and, indeed, materialized. As in the case last year in anticipation of Tropical Storm Irene, substantial numbers of citizens defied the mandate and stayed. This suggests that much work is needed to better understand why people should or should not evacuate pre-emptively, and how to effectively communicate to at-risk populations before and during a crisis.

However, for those of us in the fields of disaster medicine and public health preparedness, the question is, were we ready? During the past decade considerable public investment has been made in standardizing command and communication, assuring appropriate and rapid supply chains, and training the medi$\mathrm{cal}$ and public health workforces to respond appropriately. And yet, in the week after the storm, persistent reports of widespread gaps in the provision of coordinated relief were received from the Rockaways to Coney Island to Staten Island and New Jersey. The question was not one of capacity and capability as much as it was of communication and coordination. Resources did not always make it the last mile to reach those most in need.

Nor was this event entirely unexpected. Just as the fictional 2004 Hurricane Pam exercise in Louisiana foreshadowed the 2005 Hurricane Katrina, a 2011 hurricane evacuation study commissioned by the US Army Corps of Engineers and the New York City Office of Emergency Management had ominous echoes of what was to come. The authors noted that, "The region's unique and severe vulnerability to storm surge and winds associated with coastal storms cannot be overstated. The region has been impacted historically by major hurricanes but one has not hit in recent history with the levels of population and infrastructure that are now in place. Many residents and businesses while 'street smart' regarding every day urban issues, are inexperienced in dealing with the direct impacts of a major storm event."

Climate scientists have also predicted this storm surge for years. One 2011 report from the Earth Institute mapped a coastal storm event that mirrored Sandy's footprint. The authors warned of "structural damage and impaired operations of communications, energy, transportation, and water and waste infrastructure; reduction of water quality through saltwater intrusion into aquifers; and inundation of low-lying areas and wetlands." The handwriting on the wall has been clear.

The recovery from Sandy's devastation has only just begun. And, unfortunately, true recovery from large-scale disasters is invariably a prolonged and complex challenge that is poorly understood and difficult to accomplish, whether here in the United States or elsewhere in the world. That said, some lessons should 
be derived from the experience with Sandy_-lessons that should have been learned from past disasters as well. Communication is critical, at all levels and to all who are affected. Directing people to websites or Twitter feeds is of little use if they have no power to charge their cellphone. Coordination did occur, but only in fits and starts; moreover, it often happened outside the conventional channels. Efforts should be made to broaden those coordination channels to include more diverse and emergent groups. Also, as the metropolitan area turns its attention from response to recovery, and the press turns its attention away completely, communities have an even greater need to consider what sustainable redevelopment can look like, and to take seriously an investment in preparedness and mitigation.

The disciplines of medicine and public health can learn lessons, again, from Sandy: to develop more integrated systems, to practice and train together, and to build redundancy into everything, whether electronic medical records or generator fuel pumps. Certainly, this storm will also serve as a test of several recent frameworks, the Centers for Disease Control's Public Health Emergency Preparedness Capabilities, and the Federal Emergency Management Agency's National Disaster Recovery Framework. Both can be refined in light of actual deployments.
Sandy has been a humbling experience for those of us who live or work in New York City, to imagine that the country's largest city, so resourceful and resource-rich, could have met its match so easily. Although the blow has been not so great that it has exceeded the city's grasp to recover. That remains to be seen, but given the city's resilience post-9/11, one can easily imagine the city rebuilding back strongly. It did reveal, however, some of the same vulnerabilities that the world witnessed in Hurricane Katrina. These include the organizational vulnerabilities of agencies, organizations, and emergent groups that still do not communicate well with one another, and the social vulnerabilities that continue to place isolated and marginalized groups in harm's way. Perhaps we will heed the lesson next time.

Author Affiliations: National Center for Disaster Preparedness, Columbia University Mailman School of Public Health, New York, New York.

\section{REFERENCES}

1. US Army Corps of Engineers. Metro New York Transportation Agencies: Hurricane Evacuation Study, Final Report. September 2011. http://www.iwr.usace .army.mil/nhp/docs/20110913_Final_Metro\%20NY\%20TDR.pdf. Accessed November 19, 2012.

2. Rosenzweig C, Solecki WD, Blake R, et al. Developing coastal adaptation to climate change in the New York City infrastructure-shed: process, approach, tools, and strategies. Clim Change. 2011;106:93-127. 